\section{$\underline{\text { Review Article }}$}

ISSN: $2581-3218$

IJDR 2021; 6(1): 16-23

Received: 06-02-2021

Accepted: 26-02-2021

(C) 2021, All rights reserved www.dentistryscience.com

\title{
A comprehensive review of impression techniques In implant dentistry
}

\author{
Shweta V Annaldasula ${ }^{*}$, Chein Shee Antoinette Yen² \\ 1 Oral and Maxillofacial Prosthodontist, Mumba, Maharsthra, India \\ 2 Dental Surgeon, Rajiv Gandhi University of Health Sciences, Karnataka, India
}

\begin{abstract}
Regardless of the demonstrable success of fixed appliances like implants for the replacements of missing natural teeth in partially and fully edentulous patients, countable hindrances still persist. A crucial role is played by impressions used in the fabrication of dental implants for the success, durability and outcome of the restoration. An impression is a three dimensional negative likeness of the future position of the implant in the oral cavity. In view of the absence of periodontal ligaments that serve as natural compensators of the slight but significant details of the impression surface, therefore, impressions in implants are very crucial for implant success. Taking this factor into consideration, the present review article emphasizes on the different types of impression techniques used in implant dentistry.
\end{abstract}

Keywords: Oral cavity, Dental implants, Impression techniques.

\section{INTRODUCTION}

Implant " to graft or insert a material such as an alloplastic substance, an encapsulated drug, or tissue into the body of a recipient." has reshaped modern day dentistry so much so to be considered a hallmark in the rising trends of daily clinical practice ${ }^{[1,2,3]}$. Excellent support, function and aesthetics for fixed as well as removable prosthesis, when compared to conventional complete and partial frameworks implants are regarded as "solution of choice" ${ }^{[4,5]}$. A passive and precise match of implant supra-structure to implant abutment determines its future success and sturdiness therefore reducing prosthetic complications ${ }^{[6]}$. The implant impression technique used is responsible for this exact transfer. Therefore, utmost importance should be placed on the accuracy and technique used in implant dentistry ${ }^{[7,8]}$.

The three-dimensional orientation of implant present intra-orally is an important factor to be taken into consideration. With development of impression techniques and materials available for impression making, it becomes important for a prosthodontist to select proper impression technique and impression material with its proper scientific knowledge for a particular case.

Although, a range of techniques for making impressions of implant retained prothesis have been evolved, each one has got their impediments. Thus the selection of a specific impression technique, which enormously affects the outcome of the treatment, still remains as a tedious task. This article highlights the various techniques of implant impressions as well as modifications pertaining to cases which require special demand in specific situations.

\section{GOALS OF IMPLANT IMPRESSION}

The goal of constructing impression in implant dentistry is to accurately relate associate degree analogue of the implant or implant abutment to the opposite structures within the dental arch like the gingival tissue around the implant fixture, fine details of the surrounding gingival tissue and occlusal details of the neighbouring teeth.

1. Capturing the position of osseo-integrated implant fixture accurately

*Corresponding author: Dr. Shweta V Annaldasula Oral and Maxillofacial Prosthodontist, Mumba, Maharsthra, India Email: avshweta90[at]gmail.com
2. Associate it to surrounding structure for fabrication of a superstructure with optimal aesthetic emergence profile.

3. Soft tissue management surrounding the implant fixture.

An advanced planning is always critical to making an implant impression, also an accurate impression is vital 
in giving the patient a successful prosthesis which resembles the appearance and function of the natural tooth.

The amalgamation of all the following steps combines in making an accurate and hassle-free implant impression.

a. Identification of correct implant components.

b. Selection of custom tray - Can be stock or custom trays.

c. Choosing impression materials - accurate, easy to mix, biocompatible, dimensionally stable.

d. Selecting the screw-driver - hex - either external or internal depending on the implant-abutment system.

e. Healing caps or abutments.

f. Impression copings and abutments.

\section{CLASSIFICATION OF IMPLANT IMPRESSIONS}

The techniques for implant impressions are largely classified on the basis of:

1. The type of tray used or Impression coping:
a. Open-tray (Pick-up) Impression
b. Closed-tray (Transfer) Impression

2. The objective of making an Impression:
a. Primary Impressions
b. Secondary Impressions

3. By Impression level:
a. Fixture level Implant Impression
b. Abutment level Implant Impression

\section{TECHNIQUES FOR IMPLANT IMPRESSIONS}

\section{Fixture level impressions}

The impression coping is connected to the top of the implant fixture (body of the implant). After a fixture-level impression is taken, the abutment can be selected right on the model where the superstructure can also be fabricated. The screw retained type abutment in particular can be connected to the model; the superstructure is then fabricated. [Fig.1.a]

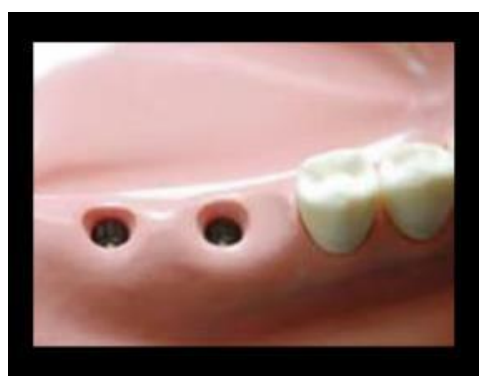

Figure 1: a. Fixture leve

\section{Abutment level impressions}

Abutment level impression is a method of taking an impression by connecting the abutments to the top of the implant fixture (body) and subsequently connecting the impression copings to them. The connected abutment in the oral cavity is not removed in the abutmentlevel impression. Therefore, until the superstructure is completed, the healing cap/gingival former should be placed to protect the connected abutment and to prevent gingival growth, to prevent any discrepancy in the impressions. [Fig.1.b]

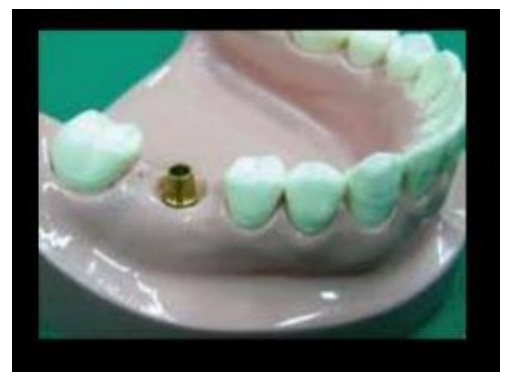

Figure 1: b. Abutment level

It has been reported that the accuracy of the implant-abutment level impression is higher when the pick-up technique is used as opposed to

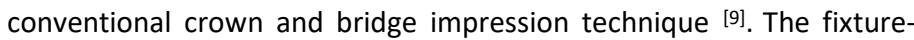
level technique failed to be as good as abutment-level technique in terms accuracy of angle of implants showing mostly linear errors. The abutment-level method showed a better linear accuracy in the case of highly diverged posterior implants. Increasing the angle of implants' divergence from $40^{\circ}$ to $60^{\circ}$ might not usually lead to a significant increase in the errors, especially when using abutment-level impressions [10].

\section{Open tray/ direct/ pick-up impressions}

The open tray impression technique is one of the commonest impression methods used. This method helps in connecting the impression coping to the fixture in the oral cavity. After the impression material hardens, unfasten the impression coping's screw procedure from the open tray. Remove the impression body, and the impression coping is removed together with the impression body from the oral cavity. [Fig.2]

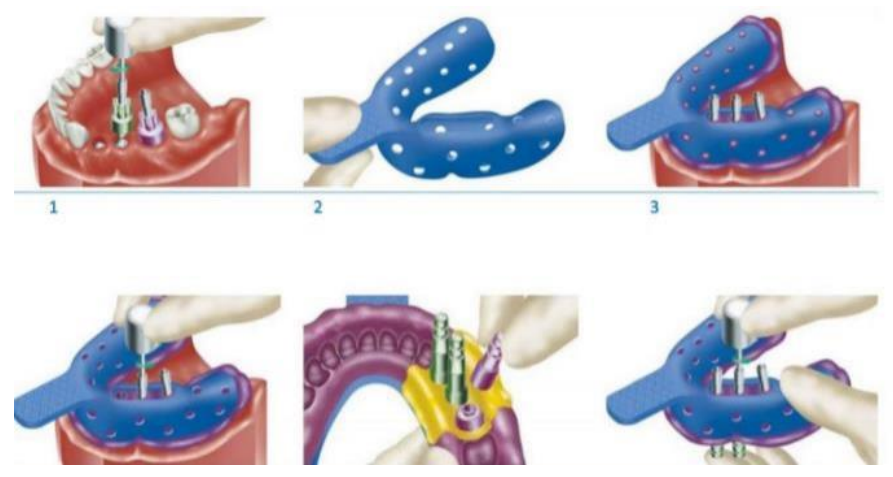

Figure 2: Open tray/Pick-up/Direct Implant Impressions

The open tray technique reduces the effect of implant angulation, deforming the impression material upon recovery from mouth, and removes the extra concern of replacing the copings into the impression [11]. The pick-up impression is named as such because the impression coping is removed together with the impression body after the impression hardens.

This technique is further sub-divided to into splinted or non-splinted techniques. This underlying principle in splinting the impression copings is to connect all the impression copings together using a rigid material to prevent the individual copings to move during the impression-making procedure.

Splinting of the transfer copings helps in preventing the rotational movement of impression copings in the impression material during analog fastening, which provides better results ${ }^{[12]}$. 
Materials used to splint impression copings include light-curing composite resin, impression plaster, thermoforming material, acrylic resin and auto-polymerizing acrylic resin using dental floss as scaffold. Recently, titanium bars were used to weld the abutments or impression analogs intraorally, making it a new procedure for splinting of implants. [Fig.3]
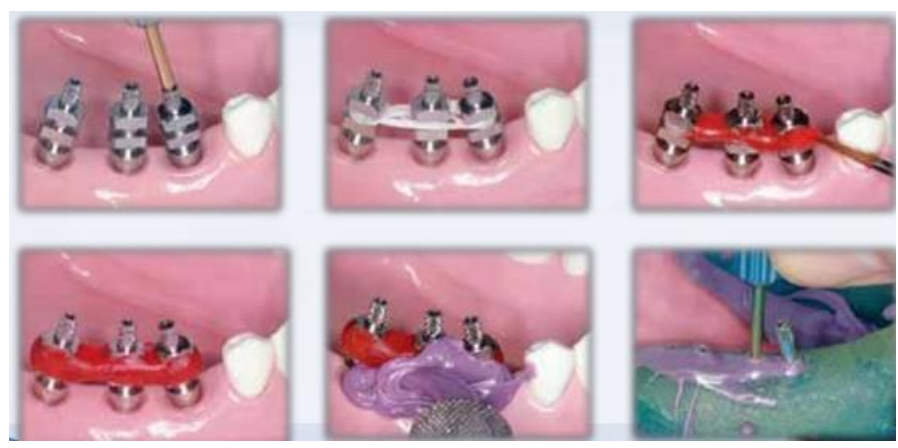

Figure 3: Splinting of Impressions using auto-polymerizing resin and dental floss as scaffold

\section{Closed tray/ indirect/ transfer type impressions}

A stock tray or a custom tray can be used in the fabrication of a closed tray impression for a fixed complete denture. The impression copings for a closed tray technique are placed on implants or multi-unit abutments and the impression made. The impression material polymerizes the impression is dislodged from the closed tray impression copings. Furthermore, the impression copings are removed and implant or abutment analogs are attached to the copings. This then goes into the impression body during what is called a transfer process. The combined coping-analog assembly is then inserted into the definitive impression. It is called the closed tray technique since impression is taken through the existing tray or based on the indirect method. Mostly these impressions are utilized for preliminary impressions ${ }^{[13]}$. [Fig.4]

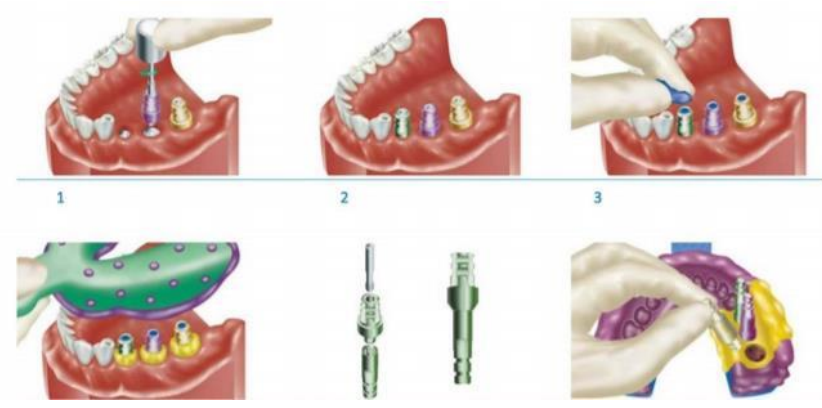

Figure 4: Closed tray/Transfer/In-direct Implant Impressions

Table 1: Type of implants and advantages

\begin{tabular}{|c|c|c|c|}
\hline & INDICATIONS & ADVANTAGES & DISADVANTAGES \\
\hline $\begin{array}{l}\text { OPEN TRAY/ PICK-UP/ } \\
\text { DIRECT IMPLANT } \\
\text { IMPRESSION }\end{array}$ & $\begin{array}{l}\text { 1.Non parallel implants } \\
\text { 2.Screw retained restoration } \\
\text { 3. Multi-unit restorations. } \\
\text { 4. Full fixed arch mandibular } \\
\text { impressions }\end{array}$ & $\begin{array}{l}\text { 1.Reduce the effect of implant angulations } \\
\text { 2.Minimizes distortion of the impression material } \\
\text { 3. The dentist can easily evaluate the laboratory } \\
\text { preparation and contour of the provisional prosthesis } \\
\text { and specify any changes required. } \\
\text { 4. Splinting helps in additional security in pick up of } \\
\text { impressions as it prevents stability and rotational } \\
\text { movement of copings }\end{array}$ & $\begin{array}{l}\text { 1.The movement of impression copings } \\
\text { inside the impression can cause } \\
\text { inaccuracy } \\
\text { 2. Rotational movement during } \\
\text { attaching of coping to implant analog } \\
\text { can occur } \\
\text { 3. Blind attachment can cause misfit of } \\
\text { the components }\end{array}$ \\
\hline $\begin{array}{l}\text { CLOSED TRAY/ TRANSFER/ } \\
\text { IN-DIRECT IMPLANT } \\
\text { IMPRESSION }\end{array}$ & $\begin{array}{l}\text { 1.Parallel level of fixture } \\
\text { insertions } \\
\text { 2. Single tooth cemented type } \\
\text { restoration } \\
\text { 3. Fabrication of provisional } \\
\text { restorations } \\
\text { 4. When the superstructure is } \\
\text { built with non-hexed } \\
\text { components } \\
\text { 5.When the patient has } \\
\text { limited inter-arch space } \\
\text { 6. Gagging tendency }\end{array}$ & $\begin{array}{l}\text { 1.Easier to perform } \\
\text { 2.Special/Custom tray not needed } \\
\text { 3. Best to manoeuvre in limited arch conditions } \\
\text { 4. Visual fastening of analogs to coping preventing the } \\
\text { blind attachment }\end{array}$ & $\begin{array}{l}\text { 1.Reinserting the copings back to the } \\
\text { respective after the impression can } \\
\text { cause distortion } \\
\text { 2. Deformation of material usually seen } \\
\text { in non-parallel implants }\end{array}$ \\
\hline
\end{tabular}

\section{Digital impressions}

With the expanding use of digital/computerized impressions, implant systems provide scan bodies that allow for capture of the relationship of the implant connection to adjacent structures more accurately through sensors. This negates or reduces the use of traditional impression materials.

The necessary needs for the CAD/CAM are the (1) the digital scanner, which scans and converts the geometry of the tooth into data that is read by the computer, (2) a software that acquires the data and changes into a 3D model, (3) a production technology that transforms the data set into the desired product by means of CAM.

In order to take a digital impression of an implant, the first thing you need to do is acquire the proper Intra-oral scan-body. Scan-bodies are specific to the brand of implant. They attach directly to the implant, much like a traditional impression coping, and are present during the digital scan. [Fig.5] 


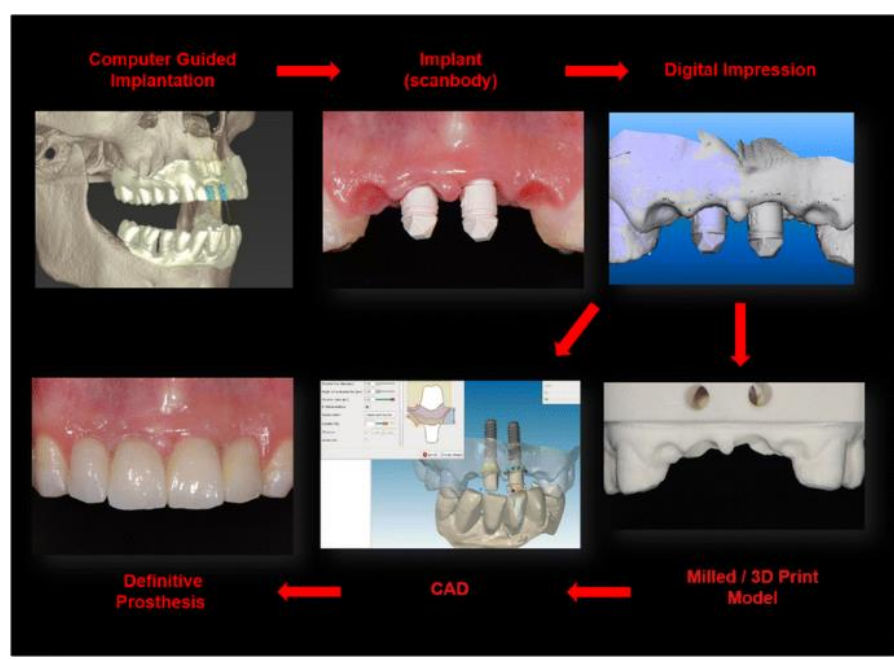

Figure 5: Digital Implant Impressions

The intraoral scanning devices utilize a ultra-modern optical surface scanning technology that works equally to a camera, however rather than merely capturing lights and colours, the sensors live lightweight reflection times from numerous surfaces through processes to capture the article three-dimensionally. This info is then captured by the three-D software package that utilizes specific alignment algorithms to permit for registration of the article. The foremost common scanning principles utilized by intraora dental scanners on the market are triangulation, active wave-front sampling, and parallel confocal optical device scanning. All of those techniques utilize a mixture of those numerous imaging capturing methodologies to gather the surface information of the teeth associated tissue layer or mucosa so the data may be registered and "stitched" along through an alignment method so as to make the virtual three-dimensional model [14].

\section{Advantages of Digital Implant Impressions:}

1. Reduced distortion of impression materials.

2. Elimination of any unpleasant taste or gagging sensation due to the dental impression materials.

3. The impressions can be viewed three dimensionally before processing.

4. Prosthetic space analysis virtually

5. Assessment of emergent profile in anterior cases specifically.

6. Reduced chair time, also reducing the number of retakes in comparison to the traditional implant impressions.

7. In the lab, the 3-D models can be evaluated for clearance, contacts, positioning of the implants and lab analogs.

\section{Disadvantages:}

1. Multiple implants can cause difficulty in identifying the correct positions of the abutments.

2. Inability to scan the surrounding soft tissue when implants are close to each other.

\section{MODIFIED IMPRESSION TECHNIQUES ACCORDING TO SPECIFIC SITUATIONS}

\section{Snap-fit technique [15]}

This technique uses press-fit impression coping which is attached to the implant by pressing rather than of screwing or cementing the copings and these are picked up in the impression. This technique is not a pick up impression because it uses a close tray. It is not called as a transfer impression as these impressions have the synthetic plastic copings being picked up during the procedure. [Fig.6]
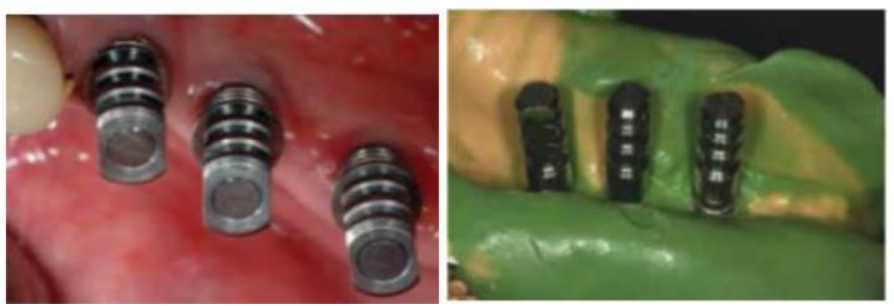

Figure 6: Snap-fit Implant Impression Technique

\section{Advantages}

1. Prevents the movement of the plastic coping

2. Reduces chair side wait time.

3. This technique has an edge because of amalgamation of both the open and closed tray implant impression techniques

4. Easier for both dentist and the patient.

The accuracy of this procedure is still under investigation, but can be a easy technique to make impressions.

\section{Implant and surrounding soft tissue contours - after stage ii surgery ${ }^{[16]}$}

To create an aesthetically pleasing soft tissue architecture around implants, several soft tissue procedures such as subtractive, additive or a combination of both could be used before stage II is uncovered.

Subtractive Technique: When there is sufficient quantity and quality of soft tissue along the edentulous crest, a subtraction technique could be used to help in reproducing and recontouring the cervical emergence contour of the required restoration with the desired labial contouring and interdental papillae. [Fig.7]

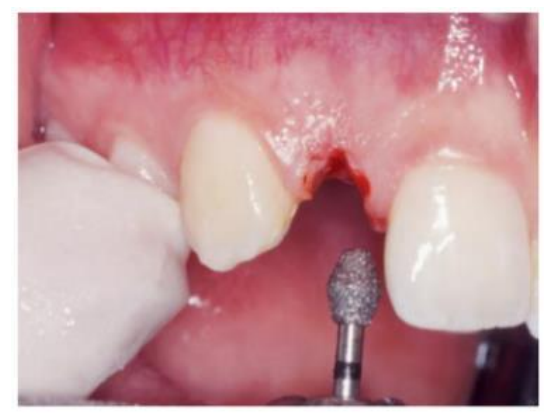

Figure 7: Substractive Technique

Addition Technique: When there is insufficient quantity and quality of soft tissue, an additive technique could be used to increase the thickness and the height of the tissue. One of the techniques states that an incision in the palatal aspect along the palatal line angle of each tooth, following by elevating the tissue till the crest of the ridge till the cover screw is identified and uncovered. A healing cap or gingival former is attached to the implant, and a removable prosthesis is recontoured accordingly for weeks over the healing cap. This causes maturation of tissue and increased quantity of tissue due to the per mucosal device. Then the final crown is restored 6-8 weeks post the tissue maturation. [Fig.8]

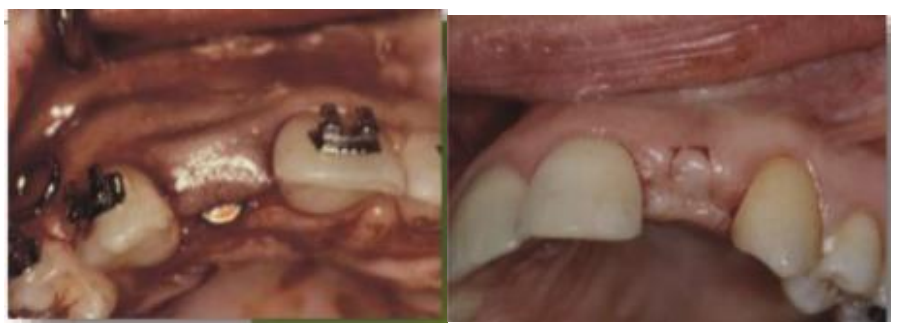

Figure 8: Additive Technique 
Several additive techniques to increase the soft tissue height around the implant have been proposed to improve the soft tissue architecture. A roll technique was originally suggested for pontic regions of a fixed partial denture using a deepithelialized connective tissue graft.

Another additive technique adopted by Dr.Carl Misch ${ }^{16}$ was a SplitFinger technique. This used when the papilla height is less than $2 \mathrm{~mm}$ from the end goal. [Fig.9]

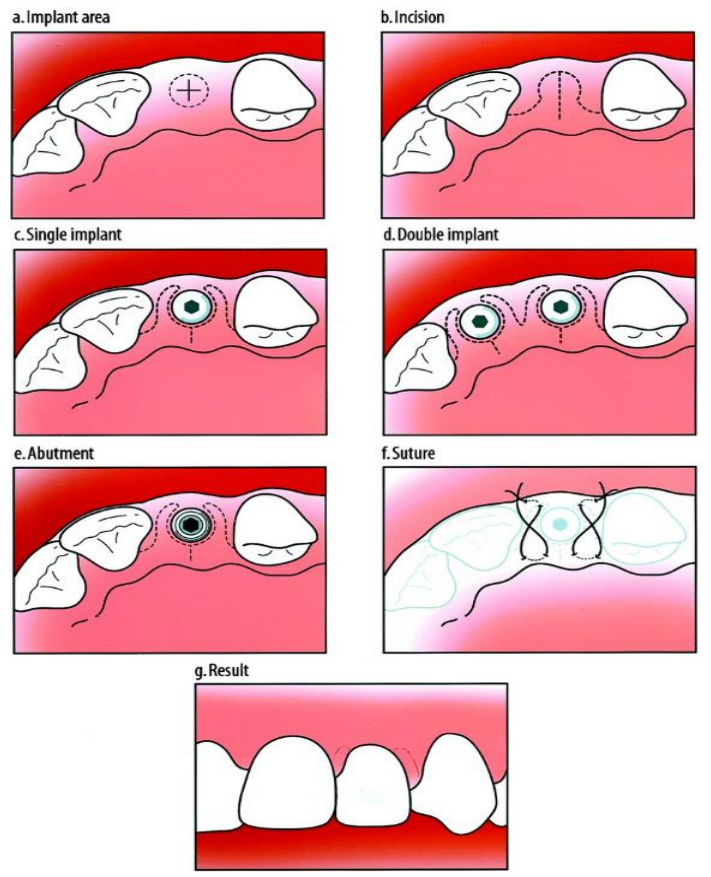

Figure 9: Split finger technique

\section{Enhancing anterior esthetics}

Post the maturation of soft tissue around the implant supported restorations, lot of techniques have been introduced to help in transfer the peri-implant soft tissue, which gradually helps in providing us with best restorations results required in anterior cases.

Enhancing the anterior aesthetics can be done in two ways, either using a temporary restoration as a coping for the pick up in final impression, or a coping that has been customised that replicates a part of the implant anatomically.

a. This procedure uses both the indirect and direct impression techniques to record and transfer the soft tissue profile around provisional restorations to a master cast ${ }^{[17]}$. [Fig.10]
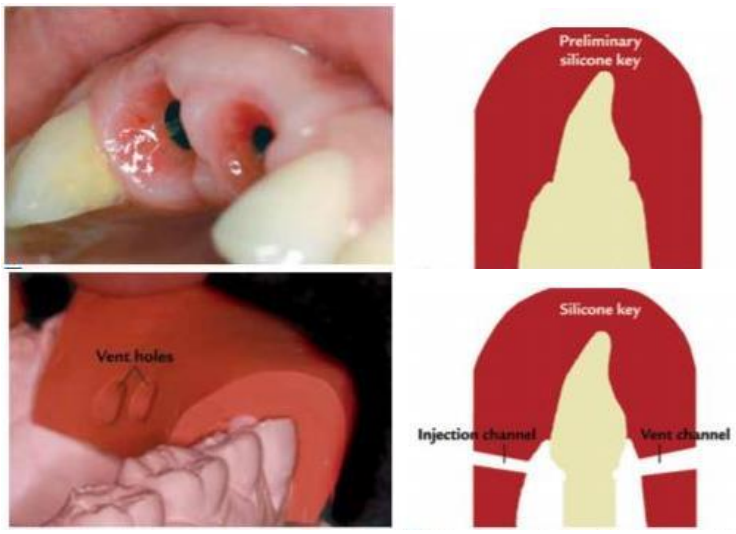
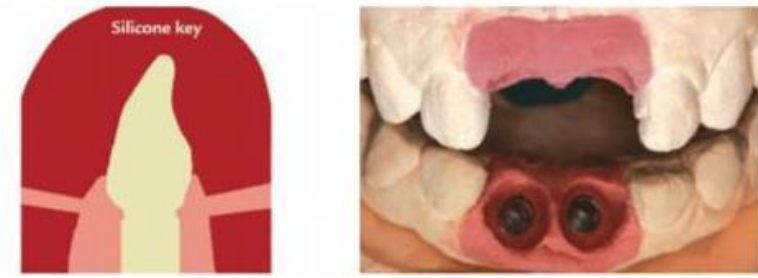

Figure 10: Accurate transfer of peri-implant soft tissue contours

b. Using provisional restorations [18]

The main concept of this technique is to identify the crown margins through the custom abutment that has been used and record the soft tissue at the same time, it helps accurate transfer of details through the provisional restoration. [Fig.11]

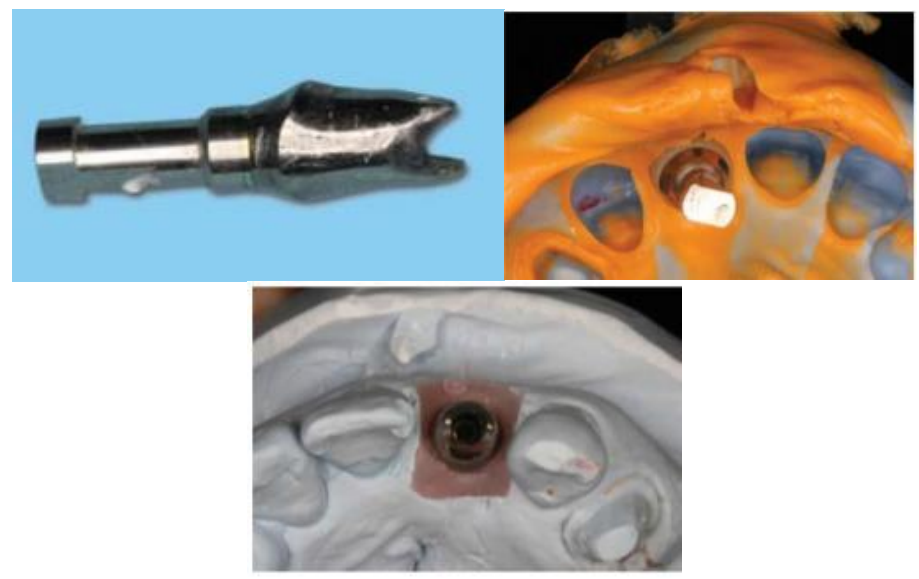

Figure 11: Using provisional Restoration

c. Customized impression copings ${ }^{[19]}$

The custom implant impression coping technique is designed to record the gingiva around the implant and pontic-receptor site after the tissues have been shaped with a provisional restoration. The technique basically consists of recording of the gingival mucosa around the implants by using a dual polymerizing composite resin that is adapted with the impression copings used for open tray, contouring it with the instruments and also taking care to prevent intrusion of material towards the implant side. This helps in increasing the accuracy of recording the soft tissue and reducing any difference between the clinical condition and laboratory cast, making it easier for technicians to sculpt the restorations well. [Fig.12]
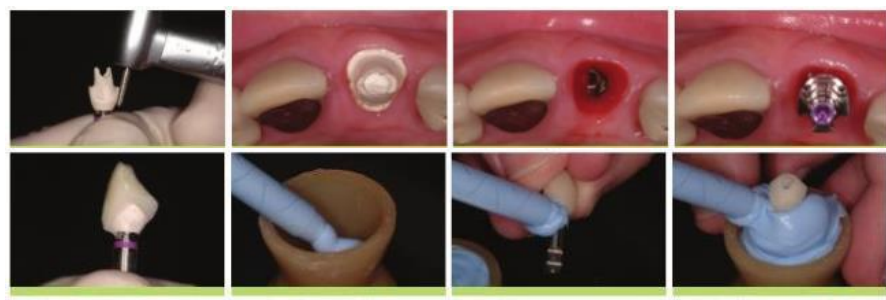

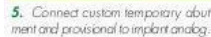
6. Fill small vessef with bile
registration materiat, suchias
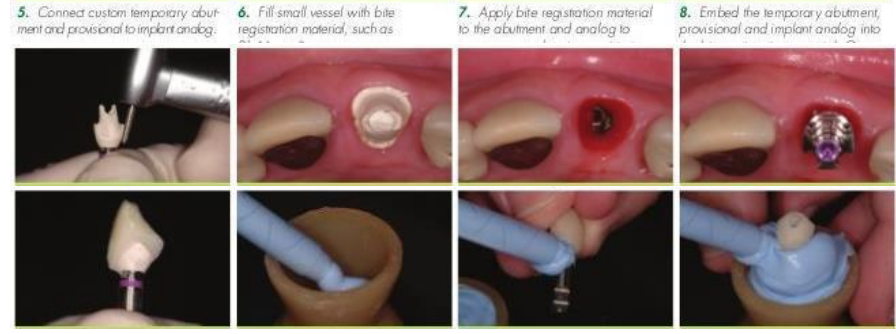


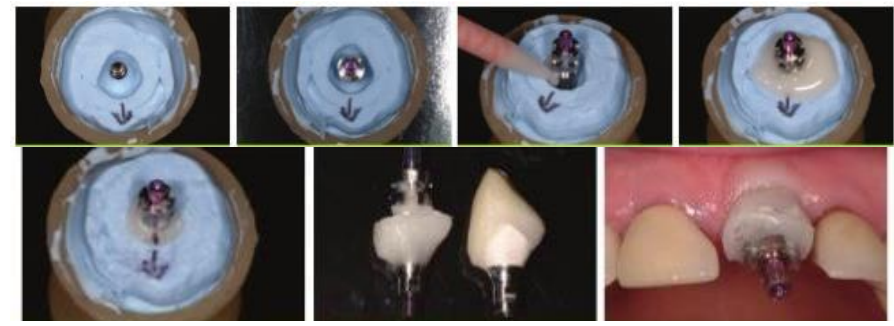

Figure 12: Using customised impression copings

\section{Implant retained overdentures}

a. Functional impression technique:

An overdenture implant impression consists of recording the soft tissue with the correct positioning of the components of implants. An implant retained overdenture has characteristics resembling those of a complete denture, with a combination of tissue support and implant retention. Thus, resilience difference between implant and mucosa should be considered for the impression of implant tissue-retained overdentures. The functional impression technique records the mucosa in a functional state and simultaneously records the implant components in relation to the alveolar tissues.

A combination of open-tray and functional impression techniques is described in this method. Border moulding and functional impression procedures are made at the same time with the use of a vinyl polysiloxane (VPS) impression material. [Fig.13]

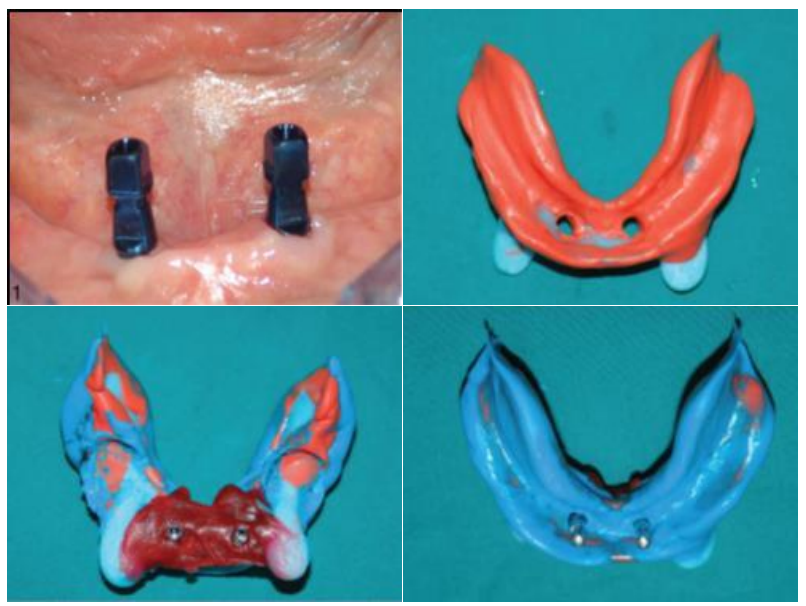

Figure 13: Functional Impression Technique

b. Two step pick up impression technique ${ }^{[20]}$

Passive fit of components is taken into account to be critical to the longterm success of implant treatment plans. Poor fit has been associated with biologic complications and component failure. Each laboratory and clinical stage may contribute to positional discrepancies in fit. Therefore, it's essential to attenuate the variation at every step within the restorative process. The process of impression making for a mandibular overdenture situation could also be vulnerable to several factors which will contribute to distortion within the final master cast. These include flexure of the mandible, distortions in the impression material, and problems with the impression procedure. The first is conventional border moulding and impression in an individualized tray that fits over the implant abutments. The second step involves attaching of the impression copings to the tray and picking up the copings from the mouth in to the impression. [Fig.14]
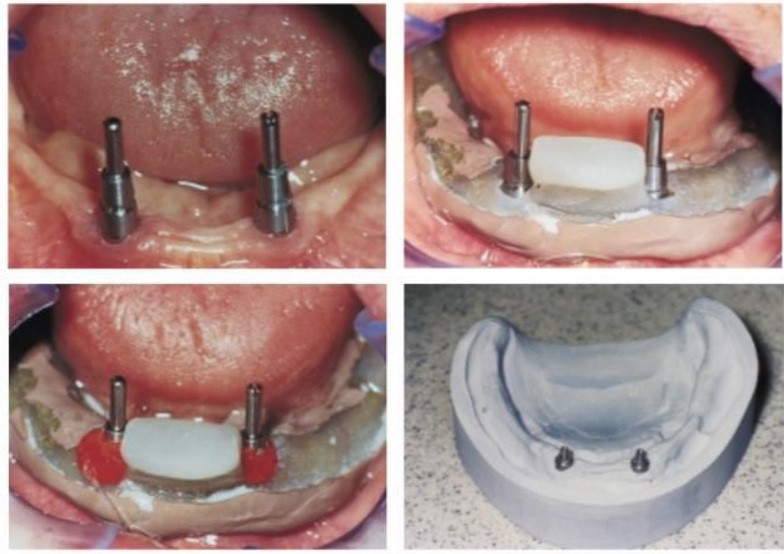

Figure 14: Two-step Implant Impression Technique

c. Dual Impression Technique:

Dual impression techniques were introduced to produce a "corrected cast" so that the teeth are recorded in anatomic and residual ridge is well. Sina Jannesar et al [21], have described a technique for a two stage selective pressure impression technique using a custom tray for implantretained over-dentures. [Fig.15]

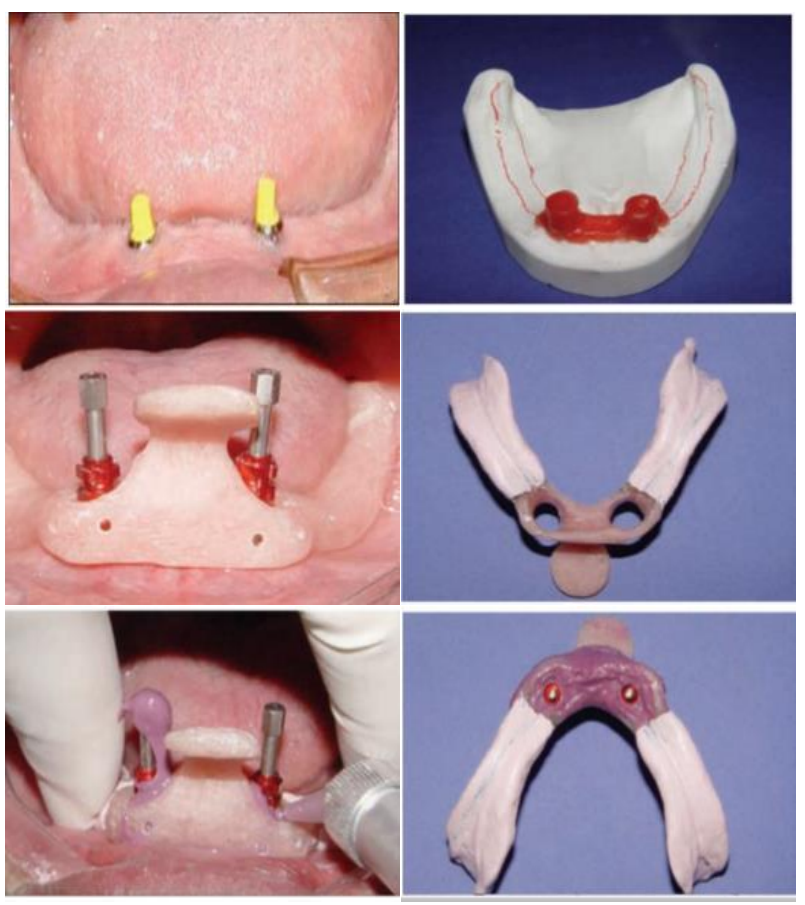

Figure 15: Dual Implant Impression Technique

\section{Deeply placed implants}

For a deeply placed implants, a solution to properly get the surrounding soft tissue is to use a longer impression coping which also increase the surface area. Though, few implants consider making a longer impression coping.

Tomas Linkevicius ${ }^{[22]}$ et al, described a simple technique using a roll of composite resin, tray adhesive, and a small amount of occlusal registration material applied around a transfer coping in a direct implant impression.

Since the hardness of occlusal registration material is more than that of the vinyl poly-siloxane (VPS), former is the material of choice for using around the impression coping to increase stability. A chunk of composite is used to surround the impression coping will helps in producing 
undercuts and also increases the surface area which in-turn helps in adhesion of impression material.

The chunk of composite helps the impressing coping to be resistant to movement when implant analog is attached and the cast is poured. As the materials are made up of the same material, A-silicone there is no risk of detachment of the occlusal registration material and vinyl poly siloxane material. [Fig.16]
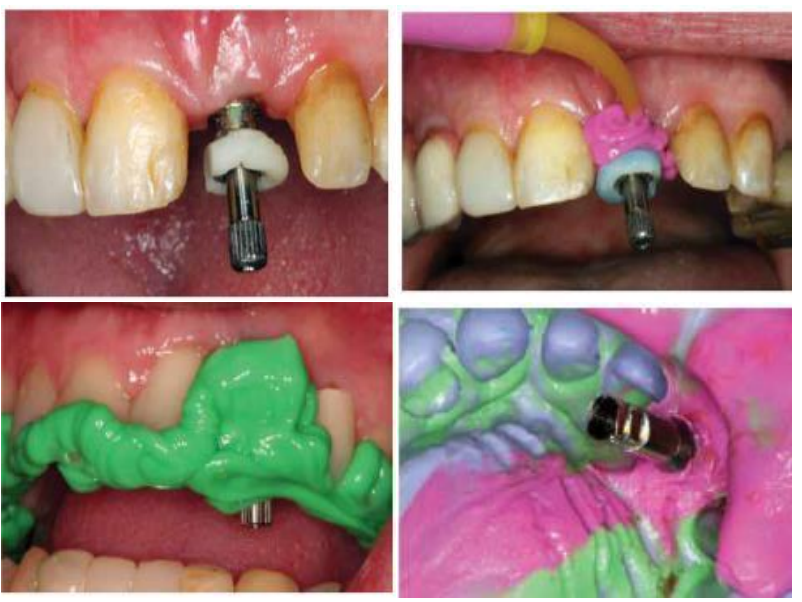

Figure 16: Impressions for deeply placed implants

\section{Implants with close proximity}

The implants which are at close proximity are difficult to manage during impression making, McCartney et al [23] introduced a technique wherein gold cylinders are used instead of impression coping for better access, Chaimattayompol ${ }^{[24]}$ et al used screw- retained titanium or frictional fit plastic index copings. [Fig.17]
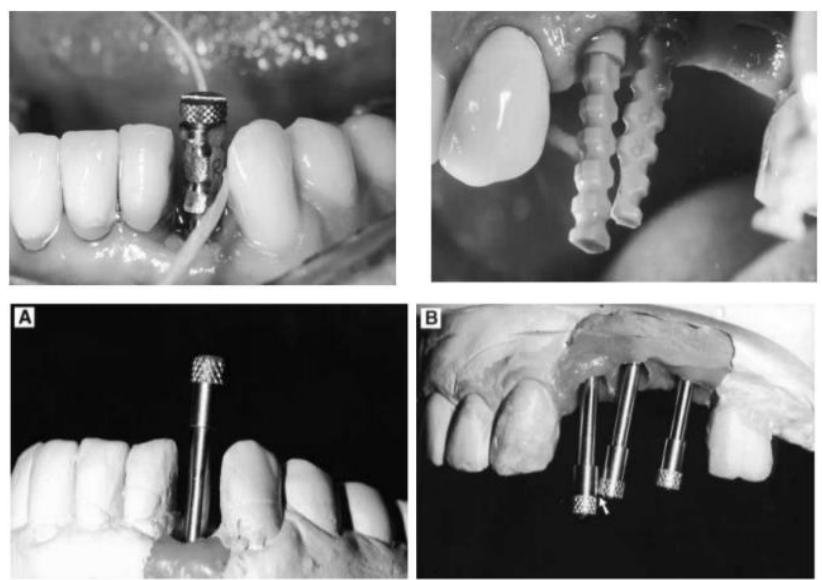

Figure 17: Impression technique for implants in Close Proximity

\section{Full arch implant impression technique [25]}

In this scenario, implant prosthesis is fabricated for the edentulous mandibular arch opposed by a maxillary denture. 4 implants placed between mental foramina help support the prosthesis and 2 implants distally in region of molars served as stops. This technique is based on the shim technique that helps to reduce the lab time and help in constructing prosthesis with less number of components and reduced cost.

\section{Advantages:}

1. Simpler laboratory fabrication.

2. Reduced chair time.

3. Compatible for both dentist and the patient.
The other technique uses only 1 set of implant impression copings and analogs, therefore need for fewer implant components. [Fig.18-22]

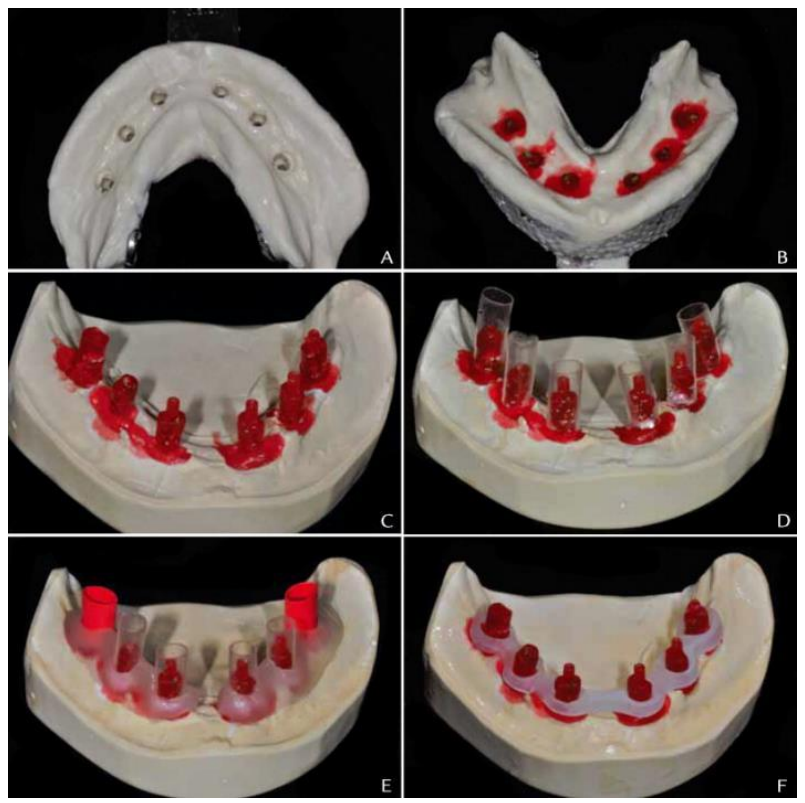

Figure 18: Full arch Implant Impression technique - Using shim method.

Preliminary irreversible hydrocolloid impression of 6 implant impression Copings, Inject thin mix of acrylic resin inside impression coping sites, Preliminary cast, Loosely cover impression copings with vinyl tubing, Wrap vinyl tubing with light polymerizing acrylic resin material and light polymerize, Shim fits around impression copings passively.

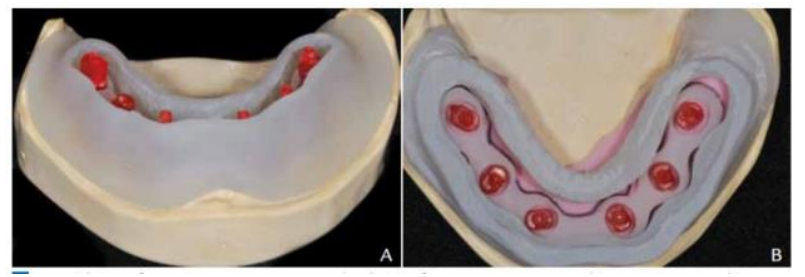

Figure 19: Facial view of open-top custom tray, Occlusal view of open-top custom tray. Shim, custom tray and impression copings fit passively

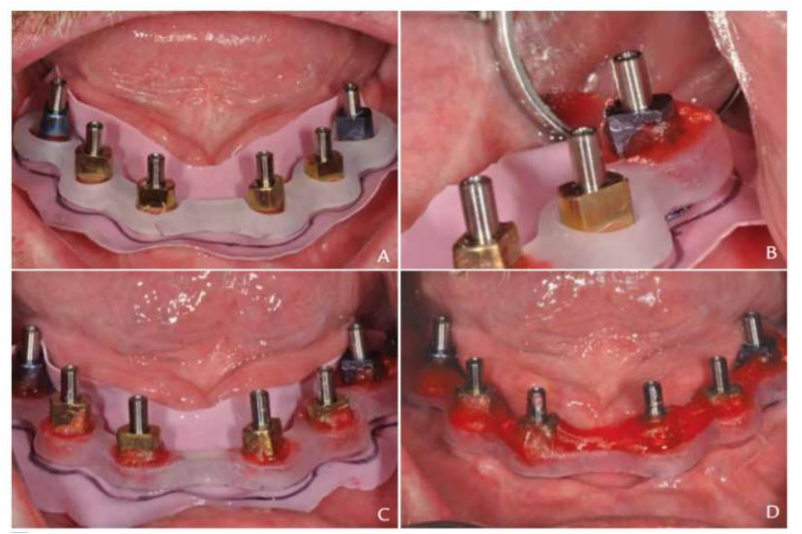

Figure 20: Place rubber dam and shim around impression copings, Lute shim and impression copings with acrylic resin, All impression copings luted to shim, Reinforce shim splinting framework after initial acrylic resin has polymerized 

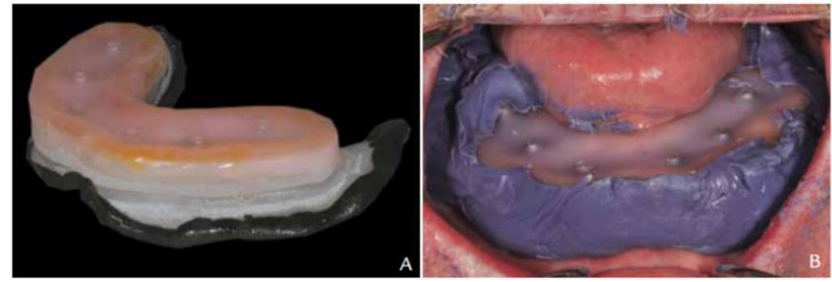

Figure 21: Seal open-top tray with 1 layer of baseplate wax. Imprint each guide pin on wax lid, Seat impression tray such that all guide pins contact underside of wax lid

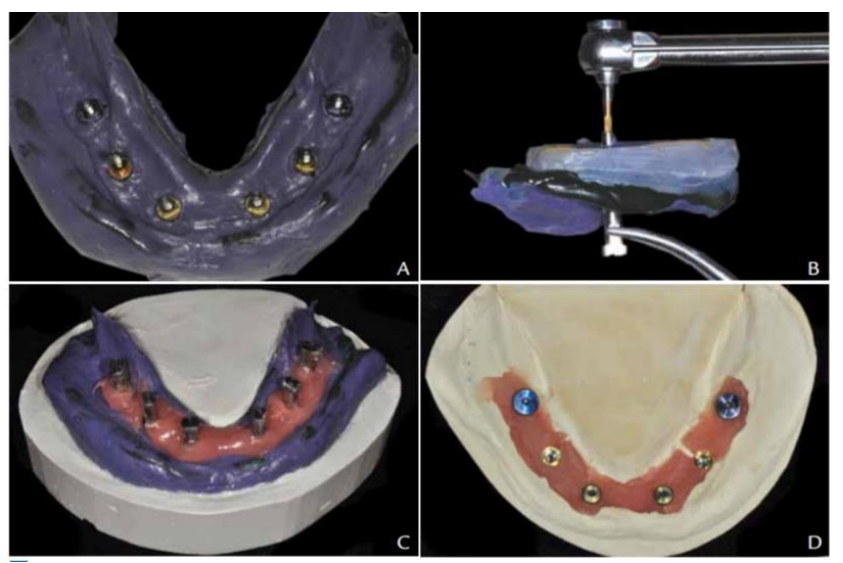

Figure 22: Intaglio surface of impression, Torque each implant replica onto impression copings to $15 \mathrm{Ncm}$ while using hemostat to counter torque, Place silicone soft tissue moulage around each implant replica, Definitive cast

\section{CONCLUSION}

The introduction of modern dental Implants alongside the foreseeable integration, has led to an emphasis on restorative techniques with added precision in the procreation of tooth comparable restorations for missing teeth. A successful implant supported prosthesis relies heavily on good impression techniques. An ideal impression records the position, depth, angulations, rotations of the hex positions, soft tissue contours or emergence profile.

Various impression procedures have their own merits and de-merits, a highly trained and proficient clinician is conscious of the many indications, contraindication, material and method of every impression technique that would lead to better results. There by, this current article aims to serve as a beginner guide in comprehending basic protocol and procedures as well as technologies in the construction and design of implant impressions.

\section{REFERENCES}

1. Misch CE. Dental implant prosthetics. Elsevier Health Sciences; 2004.

2. Bhakta S, Vere J, Calder I, Patel R. Impressions in implant dentistry. British dental journal. 2011; 211(8):361-7.

3. Sumathi K, Mantri SS, Deogade SC. Impressions in implant dentistry-A review. IJRID. 2015; 5:22-32

4. Henry PJ, Liddelow GJ. Immediate loading of dental implants. Australian dental journal. 2008; 53:S69-81.

5. Devaraju K, Rao SJ, Joseph JK, Kurapati SR. Comparison of biomechanical properties of different implant-abutment connections. Indian Journal of Dental Sciences. 2018; 10(3):180.

6. Chang BM, Wright RF. A solid bar splint for open-tray implant impression technique. Journal of Prosthetic Dentistry. 2006; 96(2):143-4.

7. Chee $\mathrm{W}$, Jivraj S. Impression techniques for implant dentistry. British dental journal. 2006; 201(7):429-32.

8. Sharma A, Chhabra A, Madan N, Madan N. Contemporary impression techniques in implant prosthodontics. Indian Journal of Dental Sciences. 2010; 2:61-2.

9. Assuncao WG, Gennari Filho $H$, Zaniquelli O. Evaluation of transfer impressions for osseointegrated implants at various angulations. Implant dentistry. 2004; 13(4):358-66.
10. Geramipanah F, Sahebi M, Davari M, Hajimahmoudi M, Rakhshan V. Effects of impression levels and trays on the accuracy of impressions taken from angulated implants. Clinical oral implants research. 2015; 26(9):1098-105.

11. Shankar YR, Sahoo S, Krishna MH, Kumar PS, Kumar TS, Narula S. Accuracy of implant impressions using various impression techniques and impression materials. Journal of Dental Implants. 2016; 6(1):29.

12. Grossmann $\mathrm{Y}$, Finger IM, Block MS. Indications for splinting implant restorations. Journal of oral and maxillofacial surgery. 2005; 63(11):164252.

13. Pandey KK. A Beginners Guide for Implant Impression: Review Article. Int J Oral Health Med Res 2017; 4(1):91-93.

14. Alikhasi $\mathrm{M}$, Alsharbaty $\mathrm{MH}$, Moharrami M. Digital implant impression technique accuracy: a systematic review. Implant dentistry. 2017; 26(6):929-35.

15. Nissan J, Ghelfan $O$. The press-fit implant impression coping technique Journal of Prosthetic Dentistry. 2009; 101(6):413-4.

16. Misch CE. Contemporary implant dentistry. 3rd edition. St. Louis: Mosby Elsevier, 2007

17. Man, Y., Qu, Y., Dam, H. G., \& Gong, P. An alternative technique for the accurate transfer of peri implant soft tissue contour. The Journal of Prosthetic Dentistry, 2013; 109(2):135-137.

18. Tsai BY. Use of provisional restorations as implant impression copings. J Prosthet Dent. 2007; 97(6):395-6.

19. Schoenbaum, Todd \& Han, Thomas. Direct custom implant impression copings for the preservation of the pontic receptor site architecture. The Journal of prosthetic dentistry. 2012; 107:203-6.

20. Gregory-Head B, LaBarre E. Two-step pick-up impression procedure for implant-retained overdentures. The Journal of Prosthetic Dentistry, 1999; 82(5):615-616.

21. Jannesar S, Siadat $H$, Alikhasi $M$. A dual impression technique for implant overdentures. Journal of Prosthodontics. 2007; 16(4):327-9.

22. Linkevicius, Tomas \& Svediene, Olga \& Vindasiute, Egle \& Linkeviciene, Laura. A technique for making impressions of deeply placed implants. The Journal of prosthetic dentistry. 2011; 106:204-5.

23. McCartney JW, Doud R. Passive adaptation of the prosthesis-implant interface by soldering golf cylinders to the framework casting. J Prosthet Dent. 1993; 70:17-20.

24. Chaimattayompol N, Emtiaz S, Woloch MM. Transforming an existing fixed provisional prosthesis into an implant-supported fixed provisional prosthesis with the use of healing abutments. The Journal of prosthetic dentistry. 2002; 88(1):96-9.

25. Ma J, Rubenstein JE. Complete arch implant impression technique. J Prosthet Dent. 2012; 107(6):405-10. 